\title{
Bortezomib overcomes the negative prognostic impact of renal impairment in a newly diagnosed elderly patient with multiple myeloma: A case report
}

\author{
TAO WU, JINMAO ZHOU, CUNBANG WANG, BINBIN WANG, SHUTING ZHANG and HAI BAI \\ Department of Hematology, Lanzhou General Hospital, Lanzhou Command, Lanzhou, Gansu 730050, P.R. China
}

Received January 11, 2016; Accepted July 14, 2017

DOI: $10.3892 / \mathrm{ol} .2017 .7151$

\begin{abstract}
Multiple myeloma (MM) is a common B-cell hematological malignancy in the clinic. Bortezomib is the first-in-class proteasome inhibitor that has been approved for the treatment of patients with MM in the bone marrow. The present study report the case of an 83-year-old man who showed marked weakness, fatigue and a poor appetite. The patient was admitted to the Department of Nephrology due to severe renal impairment (RI). Immunofixation electrophoresis indicated a $\lambda$ light chain-positive status. There were $19.2 \%$ plasmablasts and proplasmacytes in the bone marrow. Positivity for the cell surface markers cluster of differentiation (CD)13, CD33, CD38 and human leukocyte antigen-antigen D-related was detected by flow cytometry. The patient was diagnosed with MM, $\lambda$ light chain type, stage IIIB, and received bortezomib and dexamethasone regimen chemotherapy. RI was improved following the chemotherapy, and plasmablasts and proplasmacytes were almost eliminated. The $\mathrm{Hb}$ level was maintained at $\sim 90 \mathrm{~g} / \mathrm{l}$. Overall, the present case report suggests that bortezomib may be safe and effective for elderly patients, even those $>80$ years of age, with severe RI.
\end{abstract}

\section{Introduction}

As one of the most intractable malignancies, multiple myeloma (MM) has characteristics of infiltration and growth of plasma cells, the most differentiated cells in the B-cell lineage, in the bone marrow. MM typically affects elderly patients, with $\sim 33 \%$ patients are older than 75 years at diagnosis (1). MM is divided into two distinct genetic subtypes

Correspondence to: Dr Tao Wu, Department of Hematology, Lanzhou General Hospital, Lanzhou Command, 333 South Binhe Road, Lanzhou, Gansu 730050, P.R. China

E-mail:wutao2009@126.com

Abbreviations: MM, multiple myeloma; RI, renal impairment; FLCs, free light chains; MGUS, monoclonal gammopathy of undetermined significance

Key words: multiple myeloma, renal impairment, bortezomib based on chromosome content. The incidence of standard risk is $60 \%$ and median overall survival (OS) is 8-10 years. The incidence of intermediate is $20 \%$ and median OS is 4-5 years. The incidence of high risk is $20 \%$ and median overall OS is 3 years (2). Ramsenthaler et al (3) reported that the most prevalent symptoms were fatigue $(98.8 \%$, $95 \%$ CI $98.1-99.2 \%)$, pain $(73 \%, 39.9-91.7)$, constipation $(65.2 \%, 22.9-92.2)$ and tingling in the hands/feet with $53.4 \%$ (0.4-99.7). The most common problems were decreased physical functioning $(98.9 \%, 98.2-99.3)$, decreased cognitive functioning $(80.2 \%, 40-96.1)$ and financial difficulties $(78.4 \%$, 39.1-95.4). Renal impairment (RI) is a common feature of symptomatic MM and may cause major management problems (4). RI affects up to $50 \%$ of patients with MM (5). Renal failure (RF) is detected in between 20 and $30 \%$ patients at the onset of MM, and in $50 \%$ of patients during its progression (6). The prognosis of patients with MM has significantly improved following the introduction of novel concepts of immunomodulation and proteasome inhibition in myeloma therapies (7). Bortezomib is the first-in-class proteasome inhibitor that has been approved for the treatment of patients with MM in the bone marrow. The present study reports the case of a newly diagnosed MM patient, aged 83 years, in whom RI was successfully treated with a bortezomib-based regimen.

\section{Case report}

An 83 -year-old man was admitted to Lanzhou General Hospital, Lanzhou Command, (Lanzhou, Gansu, China) on February 25, 2015, due to marked weakness, fatigue and a poor appetite. The patient was admitted to the Department of Nephrology due to severe RI (Fig. 1), with $647.0 \mu \mathrm{mol} / 1$ creatinine (normal, (35-97 $\mu \mathrm{mol} / \mathrm{l}), 26.60 \mathrm{mmol} / \mathrm{l}$ urea (normal, 2.40-8.20 mmol/1), $520.0 \mu \mathrm{mol} / 1 \mathrm{uric}$ acid (normal, 90.0-420.0 $\mu \mathrm{mol} / \mathrm{l}$ ) and $8.5 \mathrm{mg} / \mathrm{l}$ cystatin-C (normal, 0.00-1.16 mg/1). Blood routine showed anemia with $61 \mathrm{~g} / \mathrm{l}$ $\mathrm{Hb}, 512 \mathrm{mg} / \mathrm{dl}$ immunoglobulin (Ig)G, $21.9 \mathrm{mg} / \mathrm{dl} \mathrm{IgA}$ and $8.5 \mathrm{mg} / \mathrm{dl}$ IgM. There were local cystic changes on the parietal bone, as determined by X-ray (Fig. 2), and an anomalous area of increased radioactivity on the left side of the 9th vertebral rib joints, as determined by Technetium-99 $\mathrm{m}$ radionuclide bone imaging (injected, $25 \mathrm{mCi}$ ) (Fig. 3). Immunofixation electrophoresis (8) indicated a $\lambda$ light chain-positive status. In 

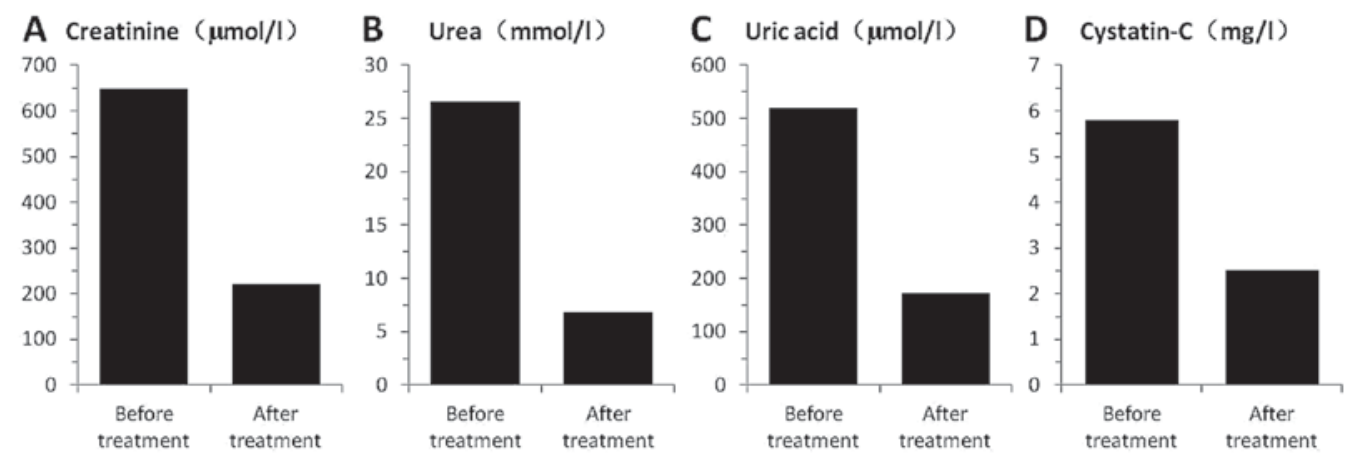

Figure 1. Kidney function was greatly improved following bortezomib treatment, as demonstrated by changes in (A) creatinine, (B) urea, (C) uric acid and (D) cystatin-C.
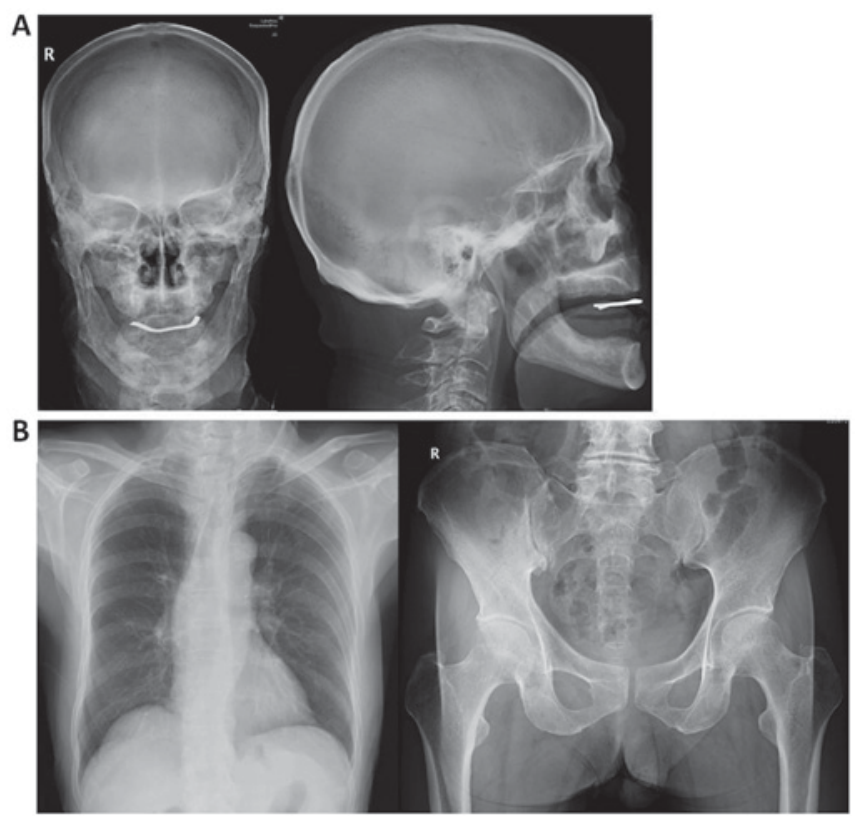

Figure 2. Radiographic representation. (A) Local cystic change on the parietal bone. (B) Normal chest and pelvic X-ray.

total, $19.2 \%$ plasmablasts and proplasmacytes were detected in the bone marrow (Fig. 4A), and the cell surface markers cluster of differentiation (CD)13, CD33, CD38 and human leukocyte antigen-antigen $\mathrm{D}$ related were positively detected by flow cytometry, as described previously (9). Chromosome analysis showed that the patient was $46, X Y$. Immunoglobulin heavy chain gene fracture restructuring was positive (14\%), as detected by fluorescence in situ hybridization of the patient's bone marrow cells (10). These specific tests were performed as MM may be accompanied by gene and chromosome mutations. For example, the patients who presented with chromosomal abnormalities del17p, $\mathrm{t}(14 ; 16)$ or $\mathrm{t}(14 ; 20)$ were genetically defined as high-risk features (7). 1q21 amplification also has very important prognostic value in multiple myeloma. Amp1q21 is one of the most common chromosomal abnormalities in patients with new-onset MM and may appear in the course of disease progression. The presence of amplq21 is an important prognostic factor and should be included in the diagnostic study at disease onset and progression (11). The patient was transferred to Department of Hematology

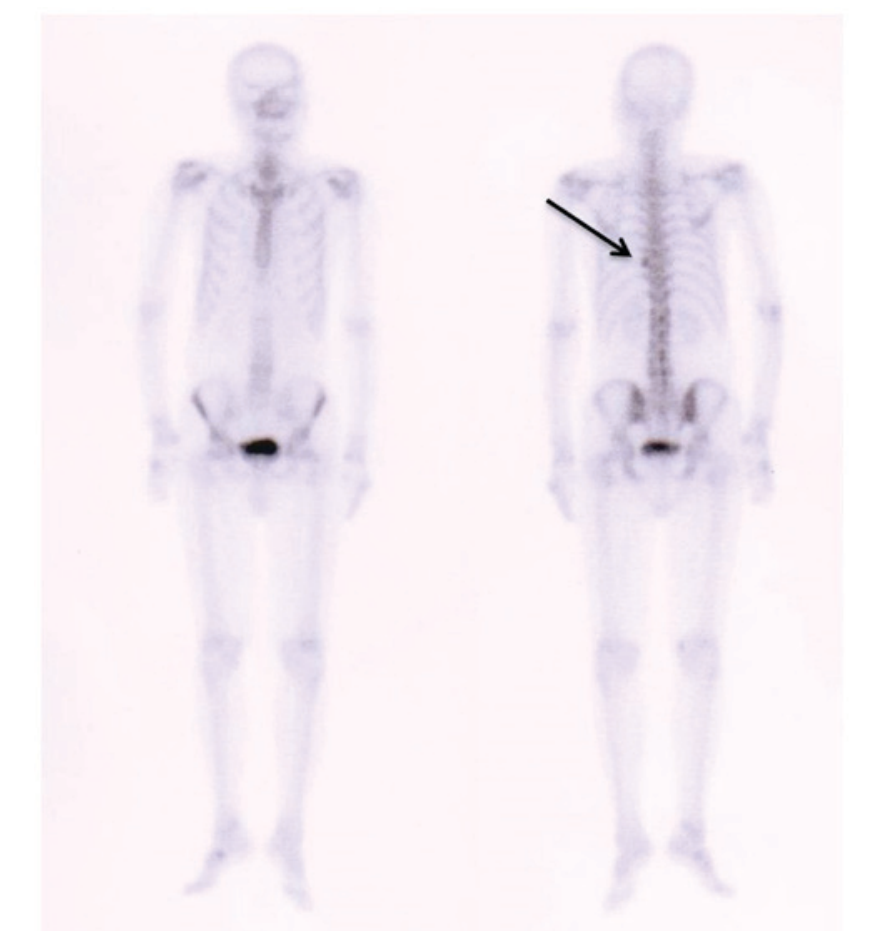

Figure 3. Anomalous area of increased radioactivity on the left side of the 9 th vertebral rib joints (arrow), as determined by Technetium- 99 m radionuclide bone imaging.

on February 28, 2015. The patient's Karnofsky performance status (12) score was 70. A diagnosis of MM, $\lambda$ light chain type, stage IIIB (Durie-Salmon system) (13), was formed, and bortezomib and dexamethasone regimen chemotherapy was administered from March 2, 2015 (bortezomib, $1.3 \mathrm{mg} / \mathrm{m} 2$, intravenous injection, days 1, 4, 8 and 11; dexamethasone, $40 \mathrm{mg}$, intravenous drip, days 1-4, 8-11). On March 1 and March $3,300 \mathrm{ml}$ red blood cells were transfused into the patient. RI was greatly improved following the bortezomib-based chemotherapy (Fig. 1), and plasmablasts and proplasmacytes were virtually eliminated, with only $0.8 \%$ mature plasmacytes left in the bone marrow (Fig. 4B). The Hb level was maintained at $\sim 90 \mathrm{~g} / 1$. The patient declined further bortezomib treatment due to numbness and pain in the hands and fingertips. On April 23, 2015, the patient was administered a melphalan and prednisone regimen (melphalan, $4 \mathrm{mg} / \mathrm{m} 2$, oral administration, days 
A B

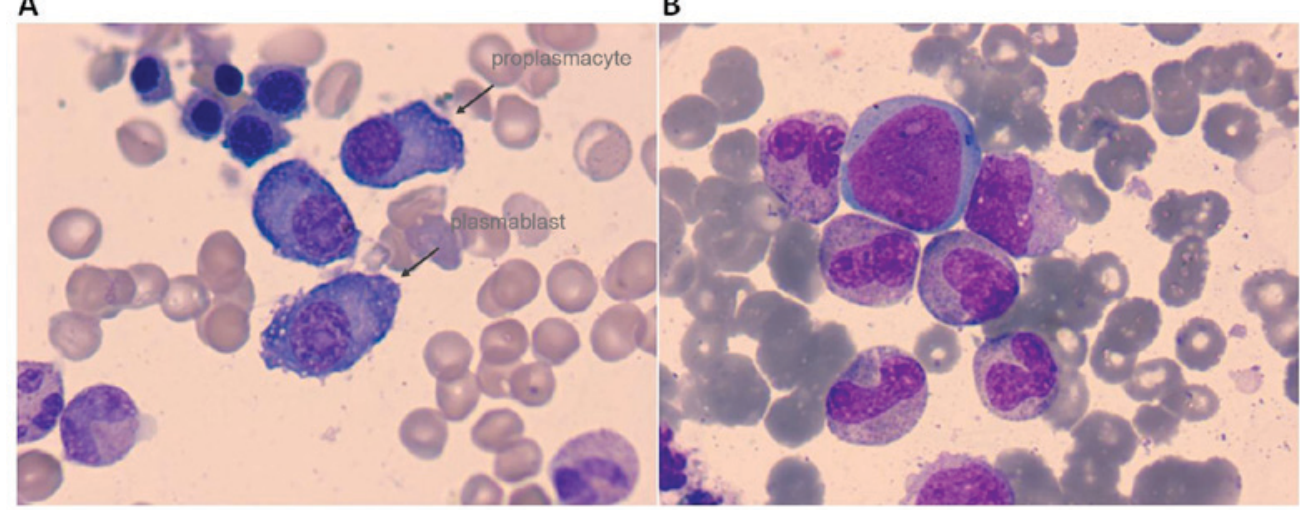

Figure 4. Plasmablasts and proplasmacytes were eradicated in the bone marrow following bortezomib treatment. (A) Prior to treatment; and (B) following treatment (magnification, $\mathrm{x} 1,000$ ).

1-4; prednisone, oral administration, $40 \mathrm{mg} / \mathrm{m} 2$, days 1-7). The patient was discharged from hospital on 28 April 2015, with $100 \mathrm{mg}$ thalidomide prescribed every night for the long-term. The patient is currently under follow-up every 4-6 weeks. Written informed consent was obtained from the patient for the publication of the present study.

\section{Discussion}

MM is a clonal B-cell malignancy that causes bone destruction and affects the immune system. Approximately $70 \%$ of myeloma patients are $>60$ years old and $90 \%$ are $>50$ years old. RI is a frequently occurring complication of symptomatic myeloma. Moderate or severe RI occurs in $20-40 \%$ of newly diagnosed patients, $10 \%$ of who may require dialysis (14-18). Antimyeloma therapy should be immediately administered for the improvement of RI.

It has been suggested in retrospective studies $(19,20)$ that the results for MM patients with RI treated with novel frontline agents may have improved such that RI may no longer have a negative prognostic impact $(21,22)$, particularly when using modern three-drug combination regimens (23).

Bortezomib is the first-in-class proteasome inhibitor that has been approved for the treatment of patients with MM; it has a half-life independent of renal clearance (24) and data from initial phase II and III trials, as well as data from patients undergoing dialysis, indicating that bortezomib is safe to use in patients with renal dysfunction $(25,26)$, even in those undergoing dialysis (27), without the requirement for dose adjustments. In addition, certain studies have indicated that, with regard to RI, the favorable activity of bortezomib may also be as a result of a protective effect on renal cells, and due to inflammatory and fibrotic cascade inhibition within the microenvironment of the kidney $(28,29)$. However, with regard to RI, rapid and marked antimyeloma action, and being non-renal metabolite, are the most significant advantages of using bortezomib (30-32). The present data showed that kidney function can rapidly be improved in MM patients, and even in older patients, such as the 83-year-old treated in the present study. The treatment appears to be safe and effective, and prospective trials $(33,34)$ showing high drug response rates of myeloma and the kidneys in patients with moderate RI, in particular to bortezomib, have further supported this stance. Another common observation is that renal response correlates with tumor response and is more common in newly diagnosed patients, compared with late-state patients $(35,36)$. The data from the present study are consistent with this observation.

There are several causes of RI in MM patients. The circulating monoclonal light chains are filtered through the glomeruli and reach the proximal tubule where they are catabolized. The free light chains (FLCs) are endocytosed by the cells of the proximal tubule through a receptor-mediated process, which results in their degradation within lysosomes (37-40). Focal loss of microvilli and inhibition of Na-K-ATPase pumps may lead to reabsorption defects (41). Cast nephropathy is another potential cause of RI. In a recent study, 24-h urine protein containing $<25 \%$ albumin exhibited a sensitivity of 0.98 , a specificity of 0.94 , a positive predictive value of 0.75 and a negative predictive value of 0.99 for the diagnosis of cast nephropathy (42).

For oliguria cases or when renal function is deteriorating rapidly or during recovery, urine quantification of light chains is unreliable. Serum FLCs have been used for the assessment of patients with light chain amyloidosis and for patients with oligo-secretory disease (43); however, in patients with RI and a significant load of FLCs, the evaluation is not straightforward. In patients with RI, $\kappa$ and $\lambda$ light chains increase and the normal $\kappa / \lambda$ ratio is different than in patients with normal renal function $(44,45)$. The current response criteria for patients with measurable disease do not use the serum FLCs but the urine 24-h light chain output (46). Furthermore, the correlation of urine light chain excretion and serum FLC levels is not linear, and large variations occur (46). Thus, in patients with significant RI, the evaluation of response to chemotherapy may be challenging.

Serum cystatin- $\mathrm{C}$ is a sensitive marker of renal dysfunction that has been applied by nephrologists for a number of years. Terpos et al (47) measured serum cystatin-C levels in newly diagnosed and pretreated patients with MM and revealed that levels were increased in patients with myeloma, even in individuals with normal serum creatinine levels. Markers of renal damage, including neutrophil gelatinase-associated lipocalin and kidney injury molecule-1 in the serum and/or 
urine, are increased in patients with monoclonal gammopathies, indicating that renal damage is present at an early in the disease course (48). The present results showed that cystatin- $\mathrm{C}$ decreased more than 1-fold following bortezomib treatment. This is consistent with the results described by Terpos et al (47). The suggestion that a decrease in estimated glomerular filtration rate of $>35 \%$ within 1 year, without any other identifiable cause, could be used as an indication for therapy is being considered. Reversal of renal dysfunction and significant improvement of renal function have been observed in several studies of patients with MM-related RI, and even certain patients on dialysis became dialysis-independent following treatment with bortezomib (27). However, it is also notable that certain patients who do not achieve an objective myeloma response may also show a significant improvement in renal function (33). Overall, significant improvement of renal function was observed in $77-82 \%$ of patients treated with bortezomib-based therapy (20). Furthermore, this improvement appears to be independent of the dose of steroids, although higher doses of dexamethasone may be associated with a shorter time to renal recovery (20).

Although novel therapeutic agents, including the proteasome inhibitor ixazomib and the immunomodulatory drug pomalidomide have been introduced, the prognosis of MM patients remains worse than that of the majority of other hematological malignancies $(49,50)$. In order to achieve any improvements in treatment outcome for MM patients, it is necessary that the molecular pathogenesis of the disease is understood to a greater extent. A phase of asymptomatic expansion of clonal plasma cells, also known as monoclonal gammopathy of undetermined significance (MGUS), is progressed through by all MM cases $(51,52)$. The linear evolution of MM from MGUS to terminal phases, such as that of extramedullary tumors and plasma cell leukemia via the accumulation of novel mutations, is a long-held belief $(51,52)$. However, previous studies using next-generation sequencing revealed the complex genomic architecture of MM. At each progression step, novel mutations are acquired together with subclonal evolution from reservoir clones with branching patterns. Individual subclones may carry novel mutations and distinct phenotypes, including that of drug sensitivity (53). Furthermore, at the MGUS stage, minor clones are already present, which could expand further along in the clinical course, causing relapse and/or leukemic conversion (54). The final aim of treatment is to eliminate all clones, including subclonal populations with distinct biological characteristics. This may be achievable by further the improvement of treatment strategies that reflect the genomic landscape of the disease.

In summary, the present case indicates that bortezomib is safe for MM patients $>80$ years old. The present study also proved that bortezomib can improve the RI of myeloma patients with a creatinine level of $>600 \mu \mathrm{mol} / \mathrm{l}$, and even of those patients $>80$ years old. However, further cases are required to confirm these findings.

\section{Acknowledgements}

This study was supported by a grant from the Natural Science Foundation of Gansu Province (no. 145RJZA151).

\section{References}

1. Zweegman S, Engelhardt $M$ and Larocca A; EHA SWG on 'Aging and Hematology': Elderly patients with multiple myeloma: Towards a frailty approach? Curr Opin Oncol 29: 315-321, 2017.

2. Chesi M and Bergsagel PL: Molecular pathogenesis of multiple myeloma: Basic and clinical updates. Int J Hematol 97: 313-323, 2013.

3. Ramsenthaler C, Kane P, Gao W, Siegert RJ, Edmonds PM, Schey SA and Higginson IJ: Prevalence of symptoms in patients with multiple myeloma: A systematic review and meta-analysis. Eur J Haematol 97: 416-429, 2016.

4. Dimopoulos MA and Terpos E: Renal insufficiency and failure. Hematology Am Soc Hematol Educ Program 2010: 431-436, 2010.

5. Knudsen LM, Hippe E, Hjorth M, Holmberg E and Westin J: Renal function in newly diagnosed multiple myeloma-a demographic study of 1353 patients. The Nordic Myeloma Study Group. Eur J Haematol 53: 207-212, 1994.

6. Rekhtina IG and Mendeleeva LP: Current approaches to treating of patients with multiple myeloma with renal failure: Questions and proofs. Ter Arkh 89: 112-117, 2017 (In Russian; Abstract available in Russian from the publisher).

7. Joseph NS, Gentili S, Kaufman JL, Lonial S and Nooka AK: High-risk mutiple myiloma: Definition and management. Clin Lymphoma Myeloma Leuk 17S: S80-S87, 2017.

8. Caillon H, Irimia A, Simon JS, Axel A, Sasser K, Scullion MJ, Ligneel T, Nouadje G, Moreau P and Dejoie T: Overcoming the interference of daratumumab with immunofixation electrophoresis (IFE) using an industry-developed dira test: Hydrashift 2/4 daratumumab. Blood 128: 2063-2063, 2016

9. Puig N, Sarasquete ME, Balanzategui A, Martínez J, Paiva B, García H, Fumero S, Jiménez C, Alcoceba M, Chillón MC, et al: Critical evaluation of ASO RQ-PCR for minimal residual disease evaluation in multiple myeloma. A comparative analysis with flow cytometry. Leukemia 28: 391-397, 2014.

10. Ross FM, Avet-Loiseau H, Ameye G, Gutiérrez NC, Liebisch P, O'Connor S, Dalva K, Fabris S, Testi AM, Jarosova M, et al: Report from the european myeloma network on interphase FISH in multiple myeloma and related disorders. Haematologica 97: 1272-1277, 2012.

11. Abramova TV, Obukhova TN, Mendeleeva LP, Pokrovskaya OS, Gribanova EO, Ryzhko VV, Grebenyuk LA, Nareyko MV, Solovyev MV, Votyakova OM, et al: Prognostic value of 1q21 amplification in multiple myeloma. Ter Arkh 89: 32-38, 2017 (In Russian).

12. Modesto AP, Usvyat L, Calice-Silva V, Spigolon DN, Figueiredo AE, de Moraes TP, Olandoski M, Shimakura SE, Barretti P, Kotanko P and Pecoits-Filho R: Impact of the karnofsky performance status on survival and its dynamics during the terminal year of peritoneal dialysis patients. Perit Dial Int: pii: pdi.2015.00241, 2017

13. Qian J, Jin J, Luo H, Jin C, Wang L, Qian W and Meng H: Analysis of clinical characteristics and prognostic factors of multiple myeloma: A retrospective single-center study of 787 cases. Hematology 22: 472-476, 2017.

14. Alexanian R, Barlogie B and Dixon D: Renal failure in multiple myeloma. Pathogenesis and prognostic implications. Arch Intern Med 150: 1693-1695, 1990

15. Blade' J, Fernández-Llama P, Bosch F, Montolíu J, Lens XM, Montoto S, Cases A, Darnell A, Rozman C and Montserrat E: Renal failure in multiple myeloma: Presenting features and predictors of outcome in 94 patients from a single institution. Arch Intern Med 158: 1889-1893, 1998.

16. Kyle RA, Gertz MA, Witzig TE, Lust JA, Lacy MQ, Dispenzieri A, Fonseca R, Rajkumar SV, Offord JR, Larson DR, et al: Review of 1027 patients with newlydiagnosed multiple myeloma. Mayo Clin Proc 78: 21-33, 2003.

17. Eleutherakis-Papaiakovou V, Bamias A, Gika D, Simeonidis A, Pouli A, Anagnostopoulos A, Michali E, Economopoulos T, Zervas K and Dimopoulos MA; Greek Myeloma Study Group: Renal failure in multiple myeloma: Incidence, correlations, and prognostic significance. Leuk Lymphoma 48: 337-341, 2007.

18. Torra R, Bladé J, Cases A, López-Pedret J, Montserrat E, Rozman C and Revert L: Patients with multiple myeloma requiring long-term dialysis: Presenting features, response to therapy, and outcome in a series of 20 cases. Br J Haematol 91: 854-859, 1995. 
19. Eleftherakis-Papapiakovou E, Kastritis E, Roussou M, Gkotzamanidou M, Grapsa I, Psimenou E, Nikitas N, Terpos E and Dimopoulos MA: Renal impairment is not an independent adverse prognostic factor in patients with multiple myeloma treated upfront with novel agent-based regimens. Leuk Lymphoma 52: 2299-2303, 2011.

20. Dimopoulos MA, Roussou M, Gkotzamanidou M, Nikitas N, Psimenou E, Mparmparoussi D, Matsouka C, Spyropoulou-Vlachou M, Terpos E and Kastritis E: The role of novel agents on the reversibility of renal impairment in newly diagnosed symptomatic patients with multiple myeloma. Leukemia 27: 423-429, 2013.

21. Chanan-Khan AA, San Miguel JF, Jagannath S, Ludwig H and Dimopoulos MA: Novel therapeutic agents for the management of patients with multiple myeloma and renal impairment. Clin Cancer Res 18: 2145-2163, 2012.

22. Gaballa MR, Laubach JP, Schlossman RL, Redman K, Noonan K, Mitsiades CS, Ghobrial IM, Munshi N, Anderson KC and Richardson PG: Management of myeloma-associated renal dysfunction in the era of novel therapies. Expert Rev Hematol 5: 51-66; quiz 67-68, 2012.

23. Costa LJ, Abbas J, Ortiz-Cruz KL, Kang Y and Stuart RK: Outcomes of patients with multiple myeloma and renal impairment treated with bortezomib, cyclophosphamide, and dexamethasone without plasma exchange. Eur J Haematol 89: 432-434, 2012

24. Mulkerin D, Remick S and Takimoto C: Safety, tolerability and pharmacology of bortezomib in cancer patients with renal failure requiring dialysis: Results from a prospective phase 1 study. ASH Annu Meet Abstr 110: 3477, 2007.

25. Jagannath S, Barlogie B, Berenson JR, Singhal S, Alexanian R, Srkalovic G, Orlowski RZ, Richardson PG, Anderson J, Nix D, et al: Bortezomib in recurrent and/or refractory multiple myeloma. Initial clinical experience in patients with impaired renal function. Cancer 103: 1195-1200, 2005.

26. San-Miguel JF, Richardson PG, Sonneveld P, Schuster MW, Irwin D, Stadtmauer EA, Facon T, Harousseau JL, Ben-Yehuda D, Lonial S, et al: Efficacy and safety of bortezomib in patients with renal impairment: Results from the APEX phase 3 study. Leukemia 22: 842-849, 2008.

27. Chanan-Khan AA, Kaufman JL, Mehta J, Richardson PG Miller KC, Lonial S, Munshi NC, Schlossman R, Tariman J and Singhal S: Activity and safety of bortezomib in multiple myeloma patients with advanced renal failure: A multicenter retrospective study. Blood 109: 2604-2606, 2007.

28. Ying WZ, Wang PX, Aaron KJ, Basnayake K and Sanders PW: Immunoglobulin light chains activate nuclear factor- $\kappa \mathrm{B}$ in rena epithelial cells through a Src-dependent mechanism. Blood 117: 1301-1307, 2011.

29. Sarközi R, Perco P, Hochegger K, Enrich J, Wiesinger M, Pirklbauer M, Eder S, Rudnicki M, Rosenkranz AR, Mayer B, et al: Bortezomib-induced survival signals and genes in human proximal tubular cells. J Pharmacol Exp Ther 327: 645-656, 2008.

30. Uttamsingh V, Lu C, Miwa G and Gan LS: Relative contributions of the five major human cytochromes P450,1A2, 2C9, 2C19, 2D6, and $3 \mathrm{~A} 4$, to the hepatic metabolism of the proteasome inhibitor bortezomib. Drug Metab Dispos 33: 1723-1728, 2005.

31. Pekol T, Daniels JS, Labutti J, Parsons I, Nix D, Baronas E, Hsieh F, Gan LS and Miwa G: Human metabolism of the proteasome inhibitor bortezomib: Identification of circulating metabolites. Drug Metab Dispos 33: 771-777, 2005.

32. Labutti J, Parsons I, Huang R, Miwa G, Gan LS and Daniels JS: Oxidative deboronation of the peptide boronic acid proteasome inhibitor bortezomib: Contributions from reactive oxygen species in this novel cytochrome P450 reaction. Chem Res Toxicol 19: 539-546, 2006.

33. Dimopoulos MA, Richardson PG, Schlag R, Khuageva NK, Shpilberg O, Kastritis E, Kropff M, Petrucci MT, Delforge M, Alexeeva J, et al: VMP (Bortezomib, Melphalan, and Prednisone) is active and well tolerated in newly diagnosed patients with multiple myeloma with moderately impaired renal function, and results in reversal of renal impairment: Cohort analysis of the phase III VISTA study. J Clin Oncol 27: 6086-6093, 2009.

34. Morabito F, Gentile M, Mazzone C, Rossi D, Di Raimondo F, Bringhen S, Ria R, Offidani M, Patriarca F, Nozzoli C, et al: Safety and efficacy of bortezomib-melphalan-prednisone-thalidomide followed by bortezomib-thalidomide maintenance (VMPT-VT) versus bortezomib-melphalan-prednisone (VMP) in untreated multiple myeloma patients with renal impairment. Blood 118: 5759-5766, 2011.
35. Ludwig H, Adam Z, Hajek R, Greil R, Tóthová E, Keil F, Autzinger EM, Thaler J, Gisslinger $\mathrm{H}$, Lang A, et al: Light chain-induced acute renal failure can be reversed by bortezomib-doxorubicin-dexamethasone in multiple myeloma: Results of a phase II study. J Clin Oncol 28: 4635-4641, 2010

36. Dimopoulos MA, Roussou M, Gavriatopoulou M, Zagouri F, Migkou M, Matsouka C, Barbarousi D, Christoulas D, Primenou E, Grapsa I, et al: Reversibility of renal impairment in patients with multiple myeloma treated with bortezomib-based regimens: Identification of predictive factors. Clin Lymphoma Myeloma 9: 302-306, 2009.

37. Batuman V, Dreisbach AW and Cyran J: Light-chain binding sites on renal brush-border membranes. Am J Physiol 258: F1259-F1265, 1990

38. Batuman V and Guan S: Receptor-mediated endocytosis of immunoglobulin light chains by renal proximal tubule cells. Am J Physiol 272: F521-F530, 1997.

39. Batuman V, Verroust PJ, Navar GL, Kaysen JH, Goda FO, Campbell WC, Simon E, Pontillon F, Lyles M, Bruno J and Hammond TG: Myeloma light chains are ligands for cubilin (gp280). Am J Physiol 275: F246-F254, 1998.

40. Santostefano M, Zanchelli F, zaccaria A, Poletti G and Fusaroli M: The ultrastructural basis of renal pathology in monoclonal gammopathies. J Nephrol 18: 659-675, 2005.

41. Guan S, el-Dahr S, Dipp S and Batuman V: Inhibition of Na-K-ATPase activity and gene expression by a myeloma light chain in proximal tubule cells. J Investig Med 47: 496-501, 1999.

42. Leung N, Gertz M, Kyle RA, Fervenza FC, Irazabal MV, Eirin A, Kumar S, Cha SS, Rajkumar SV, Lacy MQ, et al: Urinary albumin excretion patterns of patients with cast nephropathy and other monoclonal gammopathy-related kidney diseases. Clin J Am Soc Nephrol 7: 1964-1968, 2012.

43. Mayo MM and Johns GS: Serum free light chains in the diagnosis and monitoring of patients with plasma cell dyscrasias. Contrib Nephrol 153: 44-65, 2007.

44. Hutchison CA, Cockwell P, Harding S, Mead GP, Bradwell AR and Barnett AH: Quantitative assessment of serum and urinary polyclonal free light chains in patients with type II diabetes: An early marker of diabetic kidney disease? Expert Opin Ther Targets 12: 667-676, 2008.

45. Hutchison CA, Plant T, Drayson M, Cockwell P, Kountouri M, Basnayake K, Harding S, Bradwell AR and Mead G: Serum free light chain measurement aids the diagnosis of myeloma in patients with severe renal failure. BMC Nephrol 9: 11, 2008.

46. Durie BG, Harousseau JL, Miguel JS, Bladé J, Barlogie B, Anderson K, Gertz M, Dimopoulos M, Westin J, Sonneveld $\mathrm{P}$, et al: International uniform response criteria for multiple myeloma. Leukemia 20: 1467-1473, 2006.

47. Terpos E, Katodritou E, Tsiftsakis E, et al: Cystatin-C is a sensitive marker of renal impairment with an independent predictive value for survival in multiple myeloma; reduction post bortezomib monotherapy. ASH Annu Meet Abstr 110: 1484, 2007.

48. Dimopoulos MA, Christoulas D, Kastritis E, et al: Tubular damage is ubiquitous in newly-diagnosed patients with multiple myeloma: Comparison of three urinary and two serum markers of kidney injury. ASH Annu Meet Abstr 120: 2919, 2012.

49. Gupta N, Goh YT, Min CK, Lee JH, Kim K, Wong RS, Chim CS, Hanley MJ, Yang H, Venkatakrishnan K, et al: Pharmacokinetics and safety of ixazomib plus lenalidomide-dexamethasone in Asian patients with relapsed/refractory myeloma: A phase 1 study. J Hematol Oncol 8: 103, 2015.

50. Rychak E, Mendy D, Shi T, Ning Y, Leisten J, Lu L, Miller K, Narla RK, Orlowski RZ, Raymon HK, et al: Pomalidomide in combination with dexamethasone results in synergistic anti-tumour responses in pre-clinical models of lenalidomide-resistant multiple myeloma. Br J Haematol 172: 889-901, 2016.

51. Weiss BM, Abadie J, Verma P, Howard RS and Kuehl WM: A monoclonal precedes multiple myeloma in most patients. Blood 113: 5418-5422, 2009.

52. Agarwal A and Ghobrial IM: Monoclonal gammopathy of undetermined significance and smoldering multiple myeloma: A review of the current understanding of epidemiology, biology, risk stratification, and management of myeloma precursor disease. Clin Cancer Res 19: 985-994, 2013.

53. Bahlis NJ: Darwinian evolution and tiding clones in multiple myeloma. Blood 120: 927-928, 2012.

54. Magrangeas F, Avet-Loiseau H, Gouraud W, Lodé L, Decaux O, Godmer P, Garderet L, Voillat L, Facon T, Stoppa AM, et al: Minor clone provides a reservoir for relapse in multiple myeloma. Leukemia 27: 473-481, 2013 